\title{
Starch enzymatic susceptibility and structural, pasting and thermal properties of quinoa defatted by supercritical carbon dioxide
}

\author{
Ángela García Solaesa ${ }^{\mathrm{a}}$, Marina Villanueva ${ }^{\mathrm{a}}$, Sagrario Beltrán ${ }^{\mathrm{b}}$, Felicidad Ronda ${ }^{\mathrm{a}, *}$ \\ ${ }^{a}$ Department of Agriculture and Forestry Engineering, Food Technology, College of Agricultural and \\ Forestry Engineering, University of Valladolid, Spain \\ ${ }^{b}$ Department of Biotechnology and Food Science (Chemical Engineering Section), Faculty of Sciences, \\ University of Burgos, Spain
}

*Corresponding author. E-mail: fronda@iaf.uva.es

\begin{abstract}
Quinoa has recently been considered as an alternative oilseed crop due to the quality and quantity of its lipid fraction. Supercritical fluid extraction (SFE) was used in this work as a green process to extract quinoa oil without solvent residues. Defatted quinoa flour is a potentially valuable raw material whose performance as food ingredient needs to be established. Structural, physicochemical, pasting and thermal properties of quinoa (cv. Titicaca) defatted by supercritical $\mathrm{CO}_{2}$ extraction (DQ-SCCO 2$)$ were characterized. In vitro starch enzymatic susceptibility by Englyst method was also evaluated. Full fatted quinoa (NDQ) and quinoa defatted by hexane extraction (DQ-HX) were also evaluated in parallel. Quinoa cv. Titicaca showed a very high enzymatic susceptibility regardless its lipid content; $90 \%$ of the starch was hydrolyzed by digestive enzymes in 20 minutes in the three samples. Defatted quinoa showed lower pasting temperature $\left(4-5^{\circ} \mathrm{C}\right)$ than NDQ and higher gelatinization (14\%) enthalpy. DQ-SCCO $\mathrm{SC}_{2}$ showed a disrupted and microporous structure due to the pressure of $\mathrm{CO}_{2}$ used in SFE. However, its viscometric profile was very similar to that of NDQ, opposite to that observed for DQ-HX, which was significantly lower. This denotes a physical/thermal modification of the flour as a result of the higher temperature applied during hexane extraction, $68^{\circ} \mathrm{C}$, versus $40^{\circ} \mathrm{C}$ in SFE. The work confirms the feasibility of using DQ- $\mathrm{SCCO}_{2}$ as a raw material in food applications, free of solvent residues, and with a technological quality superior to that obtained by extraction with organic solvents.
\end{abstract}

Keywords: quinoa; supercritical $\mathrm{CO}_{2}$ oil extraction; pasting properties; thermal properties; SEM; in vitro starch enzymatic hydrolysis

\section{Introduction}

Quinoa (Chenopodium quinoa Willd.) is a pseudocereal originated from the Andes of South America (Li, Wang, \& Zhu, 2016). During the last two decades, quinoa has increased attention due to its great adaptability to different growing conditions, its multiple uses, as well as the wellbalanced nutritional values (Li \& Zhu, 2017c). The Danish improved variety Titicaca was a hybrid between southern Chilean and Peruvian lines, bred and selected at the University of Copenhagen (Cocozza et al., 2013). It is the most extensively grown variety in Europe due to its adaptation to the climatic conditions (Benito-Román, Rodríguez-Perrino, Sanz, Melgosa, \& Beltrán, 2018). 
Quinoa, cultivar Titicaca, could be cultivated in drought and salt stress conditions of Mediterranean-type agroecosystems (Cocozza et al., 2013).

As early as the 1990s, quinoa was considered a potential new oil crop (Koziol, 1992, 1993). RepoCarrasco et al. (Repo-Carrasco, Espinoza, \& Jacobsen, 2003) mentioned the importance of recognizing and using the relatively high quantity of oil in quinoa. These grains can be a potential raw material for oil extraction due to the high percentage of linoleic acid and gamma and alphatocopherols (Ng, Anderson, Coker, \& Ondrus, 2006; Wejnerowska \& Ciaciuch, 2018). Besides its lipids, quinoa is rich in proteins $(\approx 15 \%)$ with an extraordinary balance of essential amino acids (Filho et al., 2017). It is particularly rich in lysine and contains more histidine and methionine + cysteine than many vegetables (Abugoch James, 2009; Koziol, 1993). Moreover, it is an important source of fibers and micronutrients such as minerals, vitamins, phytochemicals and natural antioxidants with possible nutraceutical benefits (Vega-Gálvez et al., 2010). Starch, the major component of quinoa, represents between $30 \%$ and $70 \%$ of the seed dry matter (Li \& Zhu, 2018) and determines many of the flour properties ( $\mathrm{Li} \& \mathrm{Zhu}, 2017 \mathrm{c}$ ). The physiochemical properties of quinoa starch are quite different from those of most starches, which directly affects the quality attributes of quinoa food products (Wang \& Zhu, 2016). Quinoa is also characterized by being gluten-free, which has brought a greater offer and variety of more nutritious and suitable cerealbased foods, such as bread (Turkut, Cakmak, Kumcuoglu, \& Tavman, 2016), pasta (Schoenlechner, Drausinger, Ottenschlaeger, Jurackova, \& Berghofer, 2010) and cookies (Brito et al., 2015) for people with gluten intolerance, wheat allergies, and celiac disease (Wang \& Zhu, 2016).

Quinoa oil production offers interesting coproducts (Koziol, 1993). The defatted quinoa could be considered as a potentially valuable material useful for many uses. Protein of high quality, starch of singular technological properties and saponin derivatives with pharmaceutical interest could be the most valuable coproducts of quinoa oil production (Koziol, 1993). Defatting by organic solvent extraction techniques involves heat treatment of the grain during the extraction and desolventizing processes and subsequent steps. The nutritive value and functionality of the defatted flour and grits are directly dependent upon the degree to which the product is heat treated (Russin, Boye, Arcand, \& Rajamohamed, 2011). Alternatively to the organic solvents, the supercritical fluid extraction (SFE) is used as a green process to extract high added value compounds from many different sources at mild temperatures without solvent residues (Mukhopadhyay, 2000). Flours of soy, oat and barley, among others, have been defatted by $\mathrm{SCCO}_{2}$ due to the numerous advantages mainly attributed to the higher quality of the extracted oils (Kang et al., 2017; Russin et al., 2011; Sibakov et al., 2015; Temelli, Stobbe, Rezaei, \& Vasanthan, 2013; Walters, Lima Ribeiro, Hosseinian, \& Tsopmo, 2018). In this sense, quinoa oil extracted by supercritical $\mathrm{CO}_{2}\left(\mathrm{SCCO}_{2}\right)$ presented higher tocopherol content and antioxidant capacity than quinoa oil extracted by reflux with hexane (Benito-Román et al., 2018; Wejnerowska \& Ciaciuch, 2018). Supercritical $\mathrm{CO}_{2}$ extraction also minimized the impact on proteins functionality of defatted soy flours while the use of organic solvents denatured them (Kang et al., 2017). Consequently, defatted quinoa fraction, the coproduct of quinoa oil $\mathrm{SCCO}_{2}$ extraction, should be a potentially valuable raw material with still high nutritional value and free of solvents. However, its performance as an ingredient in food applications needs to be established since it is well known that the removal of lipids affects the techno-functional properties and starch digestibility of flour (Ye et al., 2018; Srichuwong et al., 2017).

Diverse approaches have been attempted to create value from quinoa in an economic and sustainable way while minimizing the impact on quinoa's protein and starch functionality (Avila 
Ruiz, Arts, Minor, \& Schutyser, 2016; Wang \& Zhu, 2016). However, the effect of defatting quinoa by $\mathrm{SCCO}_{2}$ extraction on the microstructure, technological and nutritional properties of defatted flour has never been investigated so far. Therefore, physicochemical, gelatinization and retrogradation properties, pasting characteristics and starch enzymatic susceptibility of quinoa defatted by both SFE and reflux with hexane were established. The microstructure of the flours was also evaluated to explain the observed properties. Native (full fatted) quinoa was also included as control sample. The European quinoa cv. Titicaca, not very explored so far, was used in this study.

\section{Materials and methods}

\section{Samples and chemicals}

Seeds of quinoa (Chenopodium quinoa Willd.) cv. Titicaca were kindly provided by Extremeña de Arroces (Cáceres, Spain). According to the supplier, saponins were previously removed from quinoa seeds. Quinoa grains were ground in a ball mill (Pulverisette 6, Fritsch $\mathrm{GmbH}$ ) to get grits with particle size around $500 \mu \mathrm{m}$, the optimal particle size for an appropriate oil extraction (Benito-Román et al., 2018). The quinoa grits obtained was divided in three parts. The first one was non-defatted (NDQ). The oil content of NDQ was previously confirmed to be $7.2 \%$. The second part was defatted by Soxhlet extraction (Buchi B-811) using n-hexane as solvent (DQ$\mathrm{HX})$. The last part was defatted by $\mathrm{SCCO}_{2}\left(\mathrm{DQ}-\mathrm{SCCO}_{2}\right)$ in a lab-scale plant at $40 \mathrm{MPa}$ and $40^{\circ} \mathrm{C}$, giving these conditions the highest quality oil in terms of antioxidant activity and tocopherols profile (Benito-Román et al., 2018). The residual oil content in this sample was quantified, resulting to be $0.3 \%$.

\section{Moisture, granulometry, color characteristics and bulk density}

The moisture content of the samples was measured with the AACC Official Method 44-19 (AACC, 1999) at $130{ }^{\circ} \mathrm{C}$ during 1 hour. Flour particle size distribution, measured using a Mastersizer 3000 (Malvern Panalytical), was characterized by the mean diameter $\left(\mathrm{D}_{50}\right)$ and the dispersion $\left(\mathrm{D}_{90}-\mathrm{D}_{10}\right) / \mathrm{D}_{50}$ ) as described in Workineh et al. (Abebe, Collar, \& Ronda, 2015).

Color measurements of quinoa samples were carried out using a colorimeter PCE Instruments (PCE-CSM5) on the basis of $L^{*}, a^{*}$ and $b^{*}$ values with $10^{\circ}$ standard observer and D65 standard illuminant. The hue $(h)$ and the chroma $\left(C^{*}\right)$ were also obtained from the CIELAB coordinates. Each sample was measured five times. Color difference $(\Delta \mathrm{E})$ of each defatted sample with respect to NDQ was calculated by applying the equation: $\Delta \mathrm{E}=\left\{(\Delta \mathrm{L} *)^{2}+\left(\Delta \mathrm{a}^{*}\right)^{2}+\left(\Delta \mathrm{b}^{*}\right)^{2}\right\}^{1 / 2}$

Bulk density was determined according to Kaushal et al. (Kaushal, Kumar, \& Sharma, 2012). Quinoa samples were carefully filled into previously tared $10 \mathrm{~mL}$ graduated cylinders. The bottom of the cylinder was gently tapped several times until there was no further diminution of the sample level after filling to the $10 \mathrm{ml}$ mark. Bulk density was calculated as mass of sample per unit volume of sample $\left(\mathrm{g} / \mathrm{cm}^{3}\right)$. Each measurement was done in triplicate.

\section{Starch damage and amylose/amylopectin ratio}

The damaged starch (DS) content in quinoa samples was determined following the AACC Official Method 76-31.01 (AACC, 2014) by using a Megazyme starch damage Kit (K-SDAM). The damaged starch was expressed as $\mathrm{g} / 100 \mathrm{~g}$ of quinoa weight on a dry basis. Amylose content was determined by the lectin concanavalin A (Con A) method (Gibson, Solah, \& McCleary, 1997) using the assay kit K-AMYL of Megazyme. In both methods the absorbance was read at $510 \mathrm{~nm}$. Three replicates were made for each sample. 


\section{Scanning electron microscopy (SEM)}

A Scanning Electron Microscope (SEM) model Quanta 200FEG (FEI, Oregon, USA) was used to study the microstructure of defatted quinoa grits. The samples were mounted on aluminum stubs and sputter-coated with a $5 \mathrm{~nm}$ layer of gold using a sputter coater SCD-05 (Leica Microsystems, Wetzlar, Germany). The microstructure was visualized with an accelerating voltage of $5.5 \mathrm{keV}$ in low vacuum mode using a secondary electron detector at different magnifications.

\section{$X$ Ray Diffraction}

The diffraction assessment was performed using a Bruker-D8-Discover-A25 diffractometer (Bruker AXS, Rheinfelden, Germany) equipped with a copper tube operating at $40 \mathrm{kV}$ and 40 $\mathrm{mA}$, with $\mathrm{CuKa}$ radiation of $0.154-\mathrm{nm}$ wavelength. The diffractograms of the samples were obtained with scanning from $5^{\circ}$ to $40^{\circ}(2 \theta)$ at a rate of $1.2^{\circ} / \mathrm{min}$, a step size of $0.02^{\circ}$, a divergence slit width variable of $5 \mathrm{~mm}$ and a scatter slit width of $2.92^{\circ}$ and a nickel filter 0.02 to exclude the $\mathrm{K} \beta$ radiation. The crystallinity of samples was also determined from diffractograms based on the ratio between the global peaks area and the reduced peaks area assigned to the crystalline part of the sample and expressed as a percentage. The "search-match" software DifracEVA with PDF22004 and COD database was used for this purpose.

\section{Thermal analysis: Differential scanning calorimetry (DSC)}

Gelatinization and retrogradation transitions were assessed by DSC (DSC-822e, Mettler Toledo, SAE). Quinoa samples, $\sim 6 \mathrm{mg}$, were weighed into aluminum pans $(40 \mu \mathrm{l})$ and distilled water was added to achieve the ratio 30:70 (flour:water). The samples were scanned from 0 to $115^{\circ} \mathrm{C}$ at 5 ${ }^{\circ} \mathrm{C} /$ min using an empty sealed pan as a reference. Onset (To) and peak (Tp) temperatures $\left({ }^{\circ} \mathrm{C}\right)$, and enthalpy change $(\Delta \mathrm{H}, \mathrm{J} / \mathrm{g}$ dry starch) of endothermic transitions were recorded. After the first run, the pan was stored at $4{ }^{\circ} \mathrm{C}$ for 7 days to allow starch retrogradation. Endothermic transition of retrograded starch was determined using the same procedure. Each sample was measured in duplicate.

\section{Pasting properties: $R V A$}

Pasting properties of starch were determined by a Kinexus Pro+ rheometer (Malvern Panalytical) equipped with a starch cell. Each quinoa sample $(3.0 \mathrm{~g}$, db) was mixed with $25 \mathrm{~mL}$ deionized water before being loaded into the starch cell. The sample was first held at $50{ }^{\circ} \mathrm{C}$ for $1 \mathrm{~min}$, then heated to $95{ }^{\circ} \mathrm{C}$ at $12{ }^{\circ} \mathrm{C} / \mathrm{min}$, followed by holding at $95{ }^{\circ} \mathrm{C}$ for $2.5 \mathrm{~min}$, cooled to $50{ }^{\circ} \mathrm{C}$ at $12^{\circ} \mathrm{C} / \mathrm{min}$, and held at $50^{\circ} \mathrm{C}$ for $2 \mathrm{~min}$. The stirring rate was $160 \mathrm{rpm}$. The pasting temperature $(\mathrm{PT})$, peak viscosity (PV), trough viscosity (TV), breakdown (BD), final viscosity (FV), and setback (SB) were recorded. The viscosity was presented in Pa.s. The determination was carried out in duplicate.

\section{Starch fractions analysis}

In vitro starch digestibility was measured according to the Englyst method (Englyst, Hudson, \& Englyst, 2006) with some modifications (Abebe et al., 2015). The hydrolyzed glucose at $20 \mathrm{~min}$ (G20) and $120 \mathrm{~min}$ (G120) and the total glucose (TG) were determined by the glucose oxidase colorimetric method. Six replicates were made for each determination. The free sugar glucose (FGS) content was also determined through a separate test following the procedure proposed by Englyst et al. (Englyst, Englyst, Hudson, Cole, \& Cummings, 1999). From the above results, 
rapidly digested starch $(\mathrm{RDS})=0.9 *(\mathrm{G} 20-\mathrm{FGS})$, slowly digestible starch $(\mathrm{SDS})=0.9 *(\mathrm{G} 120-$ G20), resistant starch $(\mathrm{RS})=0.9 *(\mathrm{TG}-\mathrm{G120})$, total starch $(\mathrm{TS})=0.9 *(\mathrm{TG}-\mathrm{FGS})$ and rapidly available glucose $($ RAG $)=$ G20 were calculated. Starch digestibility rate index (SDRI) was computed from the percentage of RDS in TS in the flours (Abebe et al., 2015).

\section{Statistical analysis}

Statistical analyses were conducted using software Statgraphics Centurion XVII-X64 (Bitstream, Cambridge, MN, USA). The significance of the differences was determined based on the analysis of the variance (ANOVA) by the Tukey's honestly significant difference (HSF) method at p-value $\leq 0.05$.

\section{Results and discussion}

\subsection{Physical and chemical characteristics of the samples}

Table 1 summarizes the average particle size $\left(\mathrm{D}_{50}\right)$ and size dispersion, the color coordinates $\left(\mathrm{L}^{*}\right.$, $\left.\mathrm{a}^{*}, \mathrm{~b}^{*}, h, \mathrm{C}^{*}\right)$ and the bulk density of the three quinoa samples.

Table 1. Granulometry, color characteristics and bulk density of quinoa grits samples

\begin{tabular}{|c|c|c|c|c|c|c|c|c|c|}
\hline \multirow[b]{2}{*}{ Sample } & \multicolumn{2}{|c|}{ Average particle size } & \multirow[b]{2}{*}{$\mathrm{L} *$} & \multirow[b]{2}{*}{$a^{*}$} & \multirow[b]{2}{*}{$b^{*}$} & \multirow[b]{2}{*}{$\mathrm{C}^{*}$} & \multirow[b]{2}{*}{$\mathrm{h}$} & \multirow[b]{2}{*}{$\Delta \mathrm{E}$} & \multirow[b]{2}{*}{$\begin{array}{c}\text { Bulk density } \\
\left(\mathrm{g} / \mathrm{cm}^{3}\right)\end{array}$} \\
\hline & $\begin{array}{c}\mathrm{D}_{50} \\
(\mu \mathrm{m})\end{array}$ & $\begin{array}{c}\text { Dispersion } \\
\left(\mathrm{D}_{90}-\right. \\
\left.\mathrm{D}_{10}\right) / \mathrm{D}_{50}\end{array}$ & & & & & & & \\
\hline NDQ & 451 & 0.86 & $78.18 \pm 0.67 \mathrm{a}$ & $4.10 \pm 0.33 b$ & $13.99 \pm 0.29 c$ & $14.41 \pm 0.42 \mathrm{c}$ & $73.83 \pm 0.84 \mathrm{a}$ & - & $0.74 \pm 0.02 \mathrm{c}$ \\
\hline DQ-HX & 476 & 0.92 & $80.54 \pm 0.43 b$ & $2.72 \pm 0.28 \mathrm{a}$ & $10.69 \pm 0.32 b$ & $11.05 \pm 0.36 \mathrm{~b}$ & $75.36 \pm 0.74 b$ & 4.3 & $0.61 \pm 0.01 \mathrm{a}$ \\
\hline $\mathrm{DQ}_{-\mathrm{SCCO}_{2}}$ & 460 & 0.89 & $80.64 \pm 0.63 b$ & $2.52 \pm 0.15 \mathrm{a}$ & $9.82 \pm 0.28 \mathrm{a}$ & $10.11 \pm 0.33 \mathrm{a}$ & $75.66 \pm 0.58 b$ & 5.1 & $0.68 \pm 0.01 b$ \\
\hline
\end{tabular}

$\triangle \mathrm{E}$ : Color difference of each defatted sample with respect to NDQ. Data are the mean \pm standard deviation $(n=3)$. Values with a letter in common in the same column are not significantly different $(\mathrm{p}<0.05)$.

The average particle size values $\left(D_{50}\right)$ of quinoa samples varied from 451 to $476 \mu \mathrm{m}$. This confirms the uniformity of the particle size of the samples and allows disregarding the effect of this factor on the rest of properties. The color of the samples presented some differences (Table 1). The defatted samples, both DQ-HX and DQ-SCCO ${ }_{2}$, were lighter than the native ones, with $\mathrm{L}^{*}$ values of $\sim 81$ versus 78 of the NDQ sample. The defatted samples also showed less vivid (lower $\mathrm{C}^{*}$ values) and more yellowish hues (higher $h$ values) than the native quinoa sample. These differences, significant although not very important $(\Delta \mathrm{E} \leq 5)$, denote the loss of hydrophobic pigments in the extraction process. Similar results were previously obtained in full fat and the corresponding defatted flours from some selected seeds by Joshi et al. (Joshi, Liu, \& Sathe, 2015). Table 1 shows that the DQ-SCCO 2 sample had lower $\mathrm{C}^{*}$ than DQ-HX and a higher color difference with respect to the control (NDQ). This is coherent with our previous results that confirmed a higher tocopherol content in quinoa oil when extracted with $\mathrm{SCCO}_{2}$ than with hexane solvent (Benito-Román et al., 2018). The bulk density of quinoa grits varied from 0.61 to 0.74 $\mathrm{g} / \mathrm{cm}^{3}$ (Table 1), being the highest for NDQ. The decreased bulk density in defatted quinoa 
samples (DQ-HX and DQ-SCCO ${ }_{2}$ ) agreed with the results obtained by Joshi et al. (Joshi et al., 2015). They stated that full fat flour particles may pack closer as lipids may act as adhesives in agglomeration of the rest of molecules permitting higher bulk density. Bulk density can be used to predict packaging requirements of the flours. Furthermore, high or low bulk density of flours are looked for depending on their use in food preparations or formulation of complementary foods (Kaushal et al., 2012).

The moisture of the NDQ sample was $11.5 \%$, which is consistent with other values found in the literature for whole grain quinoa flour (Li \& Zhu, 2017c; Srichuwong et al., 2017). However, the moisture in both defatted quinoa samples was significantly reduced, mainly in DQ- $\mathrm{SCCO}_{2}(3.9 \%)$ due to the extraction process itself, as the $\mathrm{SC}-\mathrm{CO}_{2}$ could dry the sample (Brown \& Submitted, 2000). In the case of DQ-HX (9.4\%), the use of a non-polar solvent with high evaporation temperature $\left(68^{\circ} \mathrm{C}\right)$ also contributed to dry the flour.

The amount of amylose estimated by Con A binding based method was $\sim 10 \%$ of the starch, both in NDQ $(9.6 \pm 1 \%)$ and in DQ-SCCO2 $(9.7 \pm 0.5 \%)$ samples. The amylose value depends to a large extent on the method of analysis. Partly because of this, the values found in the literature for quinoa range from 0.3 to $27 \%$ ( $\mathrm{Li} \& \mathrm{Zhu}, 2018$ ). However, the majority of the studies reported a value of less than 10\% when using the Con A method (Li \& Zhu, 2017c, 2018). In our samples, as expected, the results were independent of the presence of lipids, since unlike the methods based on iodine bonding, the formation of the amylose-lipid complex does not interfere in the amylose content obtained with the Con A method.

Damaged starch (DS) was measured in the three quinoa samples as it determines the rate of water absorption and enzyme susceptibility of flours (Srichuwong et al., 2017). DS content was $2.8 \pm$ $0.1 \mathrm{~g} / 100 \mathrm{~g}$ solids in NDQ and DQ- $\mathrm{SCCO}_{2}$, and $2.5 \pm 0.1 \mathrm{~g} / 100 \mathrm{~g}$ solids in DQ-HX, so nonimportant differences were observed as a result of the defatting process. Physical damage to starch is usually attributed to the dry-milling process (Lijuan, Guiying, Guoan, \& Zaigui, 2007). These results show that the extraction process, mainly the high pressure used in supercritical extraction, did not lead to additional physical damage of starch. The high particle size of the quinoa grits studied in this work $(\approx 500 \mu \mathrm{m})$ explains our lower damaged starch values than those found in literature for quinoa flour (around $10 \%$ ) (Lijuan et al., 2007; Srichuwong et al., 2017). The similar particle size of native and defatted samples would also support their similar DS values.

\subsection{Morphology}

Scanning electron micrographs of the quinoa grits samples can be seen in Figure 1. NDQ pictures (Figures 1.A) showed that native full-fatted quinoa starch granules were presented as aggregations. The aggregates appear to be coated and joined by film-like substance. Some authors suggested that these quinoa starch aggregates are surrounded largely by a protein matrix (Abugoch James, 2009; Li \& Zhu, 2017c, 2018). Some individual dispersed starch granules can also be seen as a result of a mild milling process (Figure 1.A3). The size and morphology of individual starch granules are in agreement with previous works (Li \& Zhu, 2017c, 2018). They had a size around 1-2 $\mu \mathrm{m}$ and a polygonal shape. Defatted quinoa samples (Figures 1.B and 1.C), showed noticeable differences with respect to NDQ. After removal of the lipids, the microstructure of both DQ-HX and DQ-SCCO ${ }_{2}$ was more disordered, presenting less aggregation between the components. These results confirm that the starch aggregates, besides being embedded in a protein matrix, are also bonded to the lipids. Similar results were observed by Ye et al. (Ye et al., 2018) and Annor et al. (Annor, Marcone, Bertoft, \& Seetharaman, 2013) in their studies about the starch-protein-lipid interactions in rice and millet flours. DQ- $\mathrm{SCCO}_{2}$ (Figures 
1.C) presented more disrupted structures probably due to the pressure of $\mathrm{CO}_{2}$ used in the SFE. The formation of microporosity can also be observed in the DQ-SCCO2 sample (Figure 1.C3). These micropores would allow DQ-SCCO 2 absorbing and retaining a larger amount of water (Cappa, Lucisano, Barbosa-Cánovas, \& Mariotti, 2016).
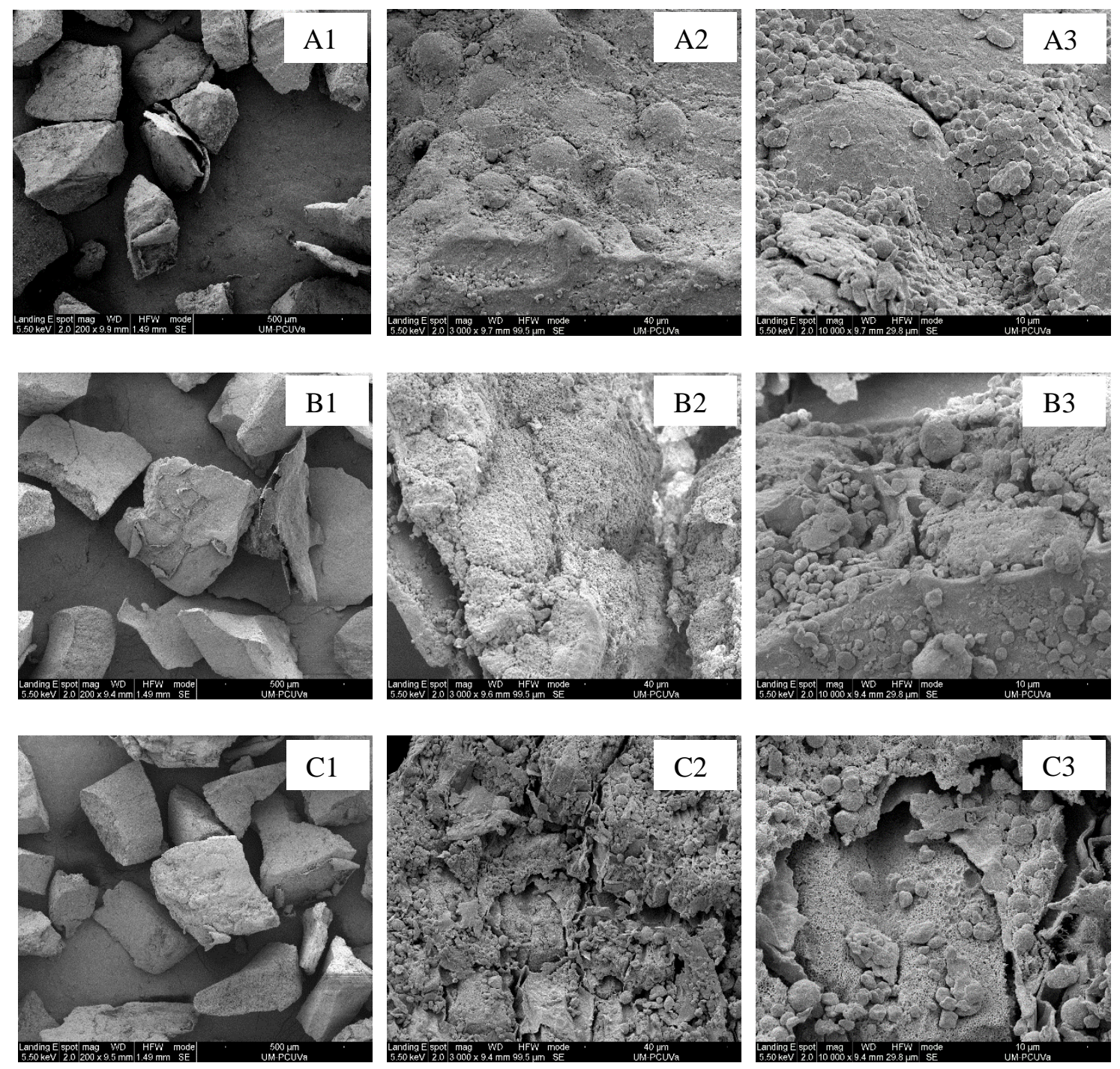

Figure 1. Scanning electron micrographs (SEM) of quinoa grits samples studied. A: NDQ; B: DQ-HX; C: DQ-SCCO 2 . (1: Magnification: × 200; 2: Magnification: × 3000, 3: Magnification: × 10,000)

\subsection{Crystallinity}

Figure 2 shows the X-ray patterns of quinoa samples. According to the characteristic X-ray diffraction lines, the starch crystal structure of quinoa corresponded to A-type polymorph, characteristic of cereal starches, with important reflections in $15.3,17,18,20$, and $23.4^{\circ}$ as reported by other authors (Li \& Zhu, 2018). The defatted samples showed no changes in the Xray diffraction patterns with respect to that of NDQ. The peak at $20^{\circ}$, indicative of the V-type crystalline structure, appeared in the three samples. This peak around $0.44 \mathrm{~nm}$ (d-spacing) is characteristic of single helical amylose, such as amylose-lipid inclusion complexes (Li \& Zhu, 2018). Other authors also found the V-type peak in starch samples defatted by different organic solvents (Vasanthan \& Hoover, 1992). This peak was not found significant for quinoa starch by 
other authors, indicating this starch has a low level of amylose-lipid complexation (Tang, Watanabe, \& Mitsunaga, 2002). The presence of the amylose-lipid complex was not observed in any of the three samples studied, including the NDQ sample, from the DSC assays (see next section 3.4). A slight reduction in the crystallinity of the three quinoa samples, from $45 \%$ in NDQ to $43 \%$ and $44 \%$ in DQ-HX and DQ-SCCO 2 respectively, was observed. These high values found for quinoa cv. Titicaca are in agreement, albeit in the superior limit, with those reported for quinoa starches of different varieties and origins (21.5 - 43\%) (Li \& Zhu, 2018).

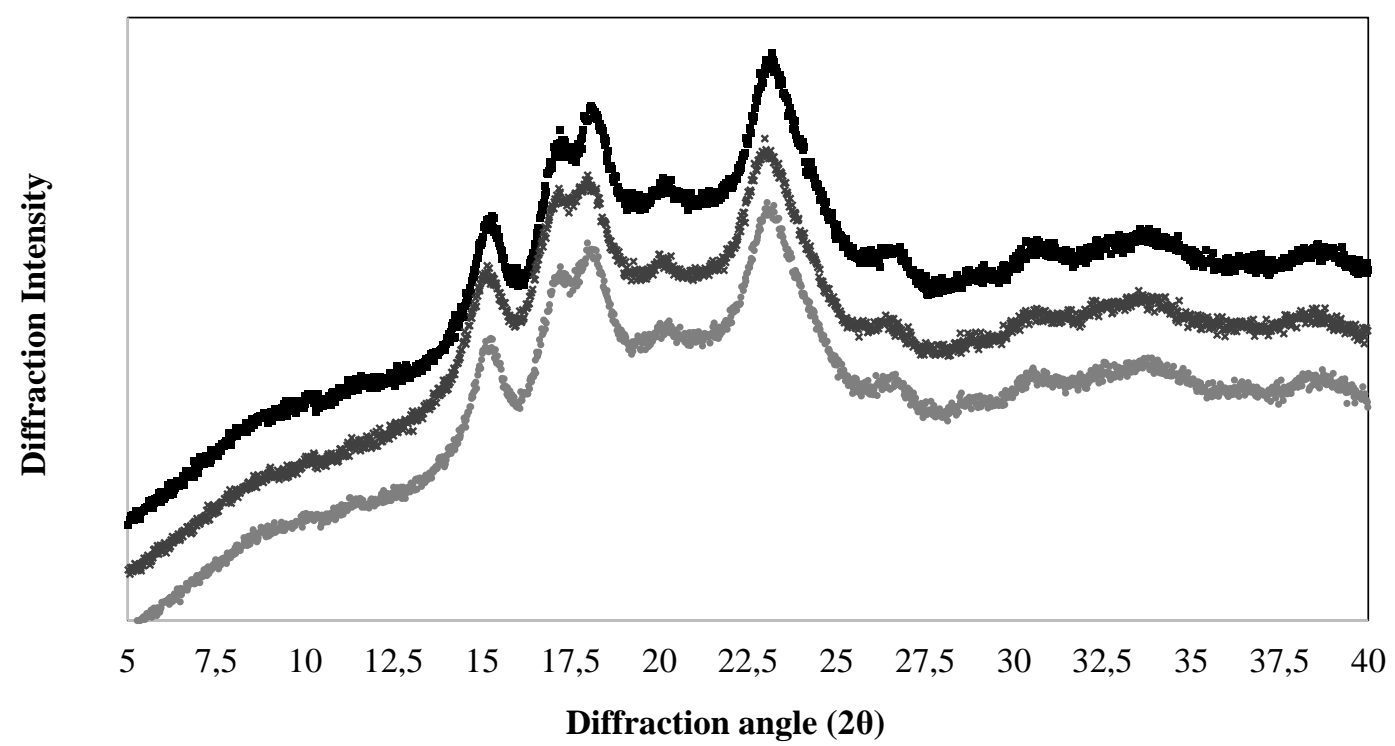

Figure 2. X-ray patterns of quinoa samples studied. Black line corresponds to NDQ, gray line to DQ$\mathrm{SCCO}_{2}$ and light-gray line to DQ-HX. The relative crystallinity for NDQ, DQ- $\mathrm{SCCO}_{2}$ and DQ-HX was 45, 44 and $43 \%$ respectively.

\subsection{Thermal properties}

The differential scanning calorimetry (DSC) of the three quinoa samples showed two wide endothermic transitions; one between $50-85^{\circ} \mathrm{C}$ and the other between $86-103^{\circ} \mathrm{C}$. The first showed a larger peak at $66{ }^{\circ} \mathrm{C}$ (Table 2) that was mainly related to starch gelatinization although another endothermic process (e.g., protein denaturation) might occur concomitantly with starch gelatinization (Li \& Zhu, 2017b, 2017c). This first peak was within the values found for whole grain quinoa flours in literature (Li \& Zhu, 2017c; Mufari, Miranda-Villa, \& Calandri, 2018). This peak appeared in the second run after 7 days of storage at $4^{\circ} \mathrm{C}$, but at lower temperature $\left(\sim 54^{\circ} \mathrm{C}\right)$ (Table 2) due to the smaller and less perfect crystallites of amylopectin recrystallized during the storage (Ronda \& Roos, 2008). However, the second endotherm did not appear in the second run. This verifies that this second endotherm, that in fact included two small peaks, corresponded to protein denaturation $\left(\sim 97^{\circ} \mathrm{C}\right)$, and not to the amylose-lipid complex dissociation. The peak corresponding to the amylose-lipid complex would appear in the first scan more or less at the same temperature but, as a reversible transition, would also appear in the second one. The protein peaks probably corresponded to A and B chenopodin subunits (11S-type globulin), the major seed storage protein of quinoa (Brinegar \& Goundan, 1993; Li \& Zhu, 2017c; Mufari et al., 2018). Other authors also reported the absence of amylose-lipid complex in quinoa flour of different varieties (Li \& Zhu, 2018). 
The relative stability of the starch granules to gelatinization was compared by measuring the onset temperature (To-gel) of the different samples (Ye et al., 2018). The To-gel values were $58.5^{\circ} \mathrm{C}$ both for NDQ and DQ-HX and $56.7^{\circ} \mathrm{C}$ for DQ-SCCO 2 (Table 2). These results suggest that the starch granules of quinoa defatted by means of SFE became more susceptible to gelatinization.

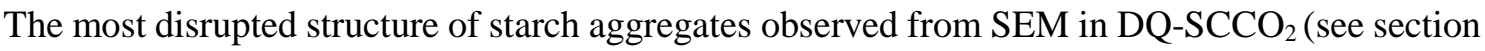
3.2) can explain its lower stability to gelatinization. However, the gelatinization enthalpy ( $\Delta \mathrm{Hgel})$ was higher in defatted quinoa samples (15.3 and $16.0 \mathrm{~J} / \mathrm{g}$ of starch in DQ-HX and DQ-SCCO respectively), than in NDQ (14.0 J/g of starch) although the difference was only significant for DQ-SCCO ${ }_{2}$. The same tendency was observed in rice flour as result of lipids removal (Ye et al., 2018). In quinoa flours of different varieties, a negative correlation between $\Delta \mathrm{Hgel}$ and their lipids content was also reported ( $\mathrm{Li} \& \mathrm{Zhu}, 2017 \mathrm{c}$ ).

Table 2. Thermal properties of quinoa grits samples.

\begin{tabular}{lccccc}
\hline Sample & $\Delta$ Hgel $(\mathrm{J} / \mathrm{g})$ & To-gel $\left({ }^{\circ} \mathrm{C}\right)$ & Tp-gel $\left({ }^{\circ} \mathrm{C}\right)$ & $\Delta$ Hret $(\mathrm{J} / \mathrm{g})$ & Tp-ret $\left({ }^{\circ} \mathrm{C}\right)$ \\
\hline NDQ & $14.0 \pm 0.8 \mathrm{a}$ & $58.4 \pm 0.3 \mathrm{~b}$ & $66.2 \pm 0.3 \mathrm{a}$ & $1.0 \pm 0.04 \mathrm{a}$ & $53.7 \pm 1.3 \mathrm{a}$ \\
DQ-HX & $15.3 \pm 0.1 \mathrm{ab}$ & $58.6 \pm 0.1 \mathrm{~b}$ & $65.9 \pm 0.4 \mathrm{a}$ & $2.2 \pm 0.1 \mathrm{~b}$ & $55.3 \pm 2.0 \mathrm{a}$ \\
DQ-SCCO2 & $16.0 \pm 0.4 \mathrm{~b}$ & $56.7 \pm 0.2 \mathrm{a}$ & $65.9 \pm 0.2 \mathrm{a}$ & $1.9 \pm 0.2 \mathrm{~b}$ & $53.5 \pm 0.5 \mathrm{a}$ \\
\hline
\end{tabular}

$\overline{\Delta H_{g e l} \text { and } \Delta H_{\text {ret }} \text { Gelatinization and retrogradation enthalpies, respectively, expressed in } \mathrm{J} / \mathrm{g} \text { of starch; } T_{\mathrm{o}}}$ and $T_{\mathrm{p}}$ : onset and peak temperatures.

Data are the mean \pm standard deviation $(n=2)$. Values with a letter in common in the same column are not significantly different $(\mathrm{p}<0.05)$

The melting enthalpy of the amylopectin retrograded during storage ( $\Delta$ Hret) was also higher in the defatted quinoa samples (Table 2) passing from $1 \mathrm{~J} / \mathrm{g}$ of starch in the full fatted sample to 2 $\mathrm{J} / \mathrm{g}$ of starch in both defatted ones. Lipids can interact with starch hindering its reorganization tendency (Li \& Zhu, 2017c). It has been clearly established that fatty acids, monoglycerides and diglycerides can be included within the central cavity of amylose and, although to a lesser extent, also in amylopectin single helices. Therefore, lipids presence hinders the recrystallization of amylopectin during the storage (Eliasson \& Ljunger, 1988). In the three quinoa samples the starch retrogradation extent was in any case low and represented less than $15 \%$ of the initial gelatinization enthalpy.

\subsection{Pasting properties}

Figure 3 shows the pasting profile of quinoa grits samples. Great variations among the pasting properties of the three quinoa samples were noted. The pasting temperature was significantly lower in both defatted quinoa samples than in NDQ, varying from 75.1 to $76.2^{\circ} \mathrm{C}$, for DQ-HX and DQ-SCCO ${ }_{2}$ respectively, to $79.2^{\circ} \mathrm{C}$ for NDQ. This must be attributed to an easier water access to starch granules when lipids are removed as lipids can restrict the granular swelling and delay the pasting transition (Ye et al., 2018). As can be seen in Figure 3, significant differences between the pasting properties of both defatted quinoa samples depending on the lipids extraction procedure were obtained. This means lipid content was not the only factor that influenced pasting properties; the extraction process and conditions applied for lipid removal affected markedly on the pasting and gelling behavior of defatted matrices (Peterson, Eller, Fanta, Felker, \& Shogren, 2008). DQ-HX sample showed the lowest viscometric profile with a constant and moderate 
increase in viscosity with time during the heating and cooling phases, reaching a final viscosity of $0.8 \mathrm{~Pa} \cdot \mathrm{s}$ at the end of the test. The lower pasting profile of the hexane extracted-sample, in comparison with the $\mathrm{SCCO}_{2}$ extracted-sample, could be due to the higher temperature applied during traditional hexane extraction in comparison to $\mathrm{SFE}\left(68^{\circ} \mathrm{C}\right.$ versus $\left.40^{\circ} \mathrm{C}\right)$ that would explain a thermal/physical modification of starch during the process. Vasanthan \& Hoover (Vasanthan \& Hoover, 1992) also noted a decrease in the pasting profile of defatted starches depending on the maximum temperatures experienced by starch granules during lipid removal and the nature and composition of the organic solvent system. Thermal energy would increase molecular mobility and allow structural changes that could explain a decrease in the swelling power of the starch and a reduction in the pasting profile of DQ-HX (Vasanthan \& Hoover, 1992). On the opposite, DQ$\mathrm{SCCO}_{2}$ presented a viscometric profile very similar to the native quinoa but with a defined peak viscosity of $1.2 \mathrm{~Pa} \cdot \mathrm{s}$ and a trough viscosity of $0.84 \mathrm{~Pa} \cdot \mathrm{s}$, not detected in the full fatted sample. The final viscosity of this sample was of $1.4 \mathrm{~Pa} \cdot \mathrm{s}$, similar to NDQ. The small but defined peak of viscosity found in $\mathrm{DQ}-\mathrm{SCCO}_{2}$ could be due to the microporosity formed in starch during the $\mathrm{SCCO}_{2}$ extraction (see section 3.2), that would explain a higher absorption of water and a superior swelling of the granules during its gelatinization (Cappa et al., 2016).

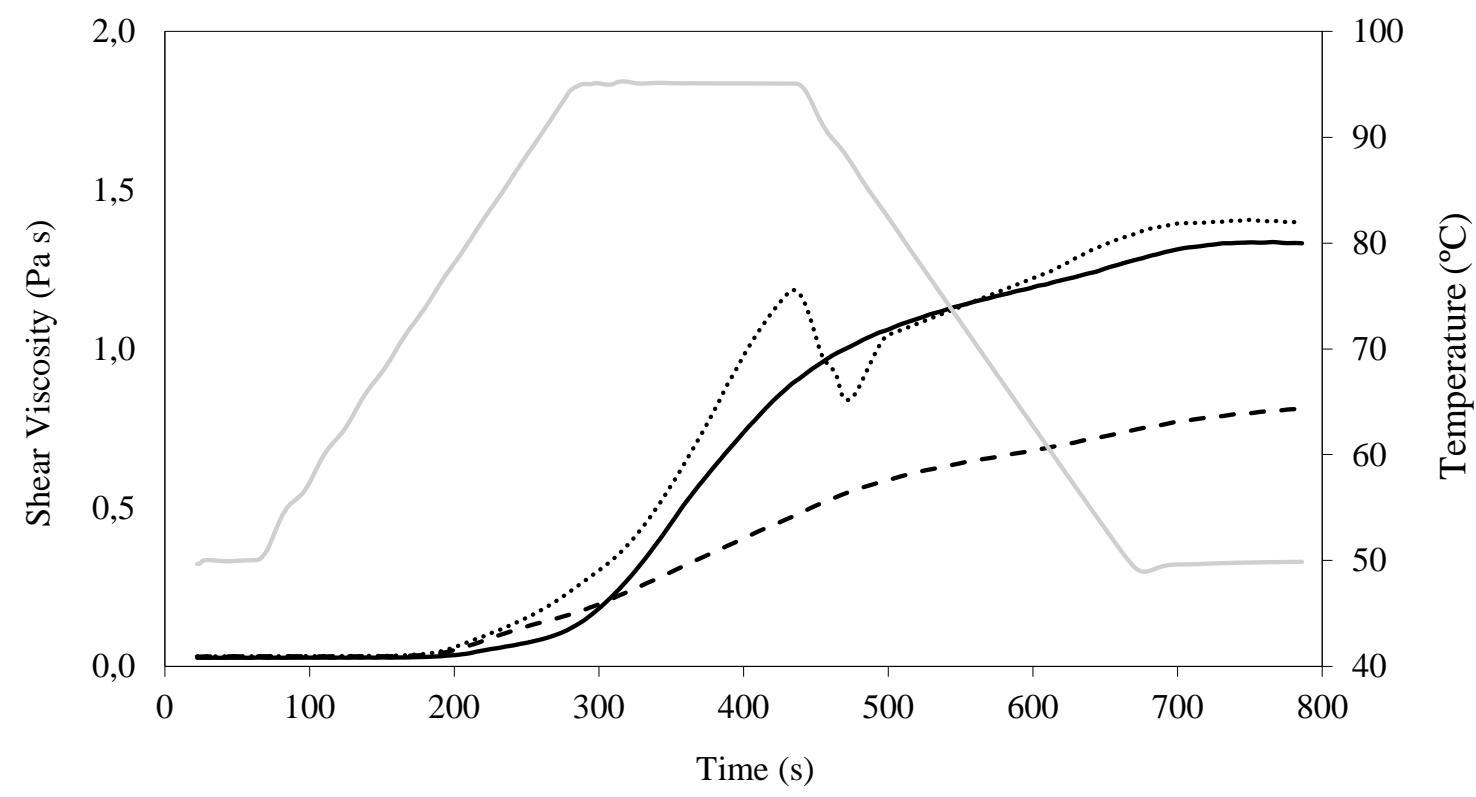

Figure 3. Pasting profiles of quinoa grits samples. NDQ (-), DQ-HX (----), DQ-SCCO $\mathrm{SC}_{2}(\ldots)$. Lightgray continuous line represents the temperature $\left({ }^{\circ} \mathrm{C}\right)$ showed in the secondary vertical axis.

\subsection{Starch fractions and in vitro starch digestibility}

Table 3 shows the starch fractions established on the basis of the rate of hydrolysis by digestive enzymes of quinoa samples depending on the presence/absence of lipids and the lipids extraction procedure. The three quinoa samples had similar in vitro starch digestibility, mainly in terms of rapidly digested starch (RDS) and starch digestibility rate index (SDRI). The amount of glucose released from quinoa grits samples was always very high (see Table 3). This is in agreement with several studies about enzyme susceptibility of quinoa starch (Li \& Zhu, 2017c, 2018; Srichuwong et al., 2017). The high enzyme susceptibility of quinoa starch can be attributed to several aspects. Firstly the small granule size of quinoa starch that leads to a high specific surface area and results 
in a higher contact with the digestive enzymes (Li \& Zhu, 2018; Srichuwong et al., 2017). The low amylose content and the less organized zones in the crystalline structures of quinoa starch granules may also influence the rate of quinoa starch hydrolysis (Srichuwong et al., 2017). Another important issue is related to the high activity of endogenous amylolytic enzymes in quinoa whole grain flour as demonstrated by Föste et al. (Föste et al., 2014) and Srichuwong et al. (Srichuwong et al., 2017). These last authors demonstrated that endogenous enzymes can hydrolyze the starch very fast if they are not inhibited by pepsin pre-incubation. The Englyst method applied in our work (Englyst et al., 2006) involves the use of a pepsin incubation step, but at a lower concentration (pepsin/substrate) than the one used by Srichuwong et al. (Srichuwong et al., 2017). This could contribute to our superior values. Our three quinoa samples from Titicaca variety had higher amounts of starch digested in 20 min (over $90 \%$ of the total starch content, with RDS values of $54-56 \mathrm{~g}$ starch/100g) than reported in literature for other quinoa varieties, usually proceeding from South America (Li et al., 2016; Li \& Zhu, 2017a; Srichuwong et al., 2017). Previous works showed that $\sim 50 \%$ of quinoa starch granules were hydrolyzed in the first hour reaching in some cases up to 80\% (Li et al., 2016; Li \& Zhu, 2017a). As can be seen in Table 3, the rapidly available glucose (RAG) content in defatted samples (65 and $66 \%$ for DQ-HX and DQ-SCCO ${ }_{2}$ ) was higher than in NDQ (63\%). The same tendency was observed in the TS content of the samples. This leads us to believe that the increase in RAG could be affected mainly by the higher starch content in the defatted samples as result of lipids removal. This was also confirmed by the SDRI values (90\%) that were the same for the three quinoa samples, regardless of the presence of lipids. The FSG values were higher in defatted quinoa samples probably because the same concentration process takes place in both samples as consequence of lipids removal. The SDS values of defatted quinoa samples $(1.1$ and $3.2 \mathrm{~g} / 100 \mathrm{~g}$ for DQ-SCCO 2 and DQ-HX respectively) were significantly lower than that of NDQ $(6.5 \mathrm{~g} / 100 \mathrm{~g})$. This can be explained by the physical barrier that lipids represent for the access of the digestive enzymes to the starch granules (Ye et al., 2018).

Table 3. Starch fractions, FSG, RAG and SDRI, quinoa grits expressed in g/100 g of dry matter.

\begin{tabular}{lccccccc}
\hline Sample & FSG & RAG & RDS & SDS & RS & TS & SDRI \\
\hline NDQ & $3.1 \pm 0.1 \mathrm{a}$ & $62.7 \pm 3.1 \mathrm{a}$ & $53.6 \pm 2.8 \mathrm{a}$ & $6.5 \pm 1.5 \mathrm{c}$ & $2.3 \pm 1.0 \mathrm{a}$ & $59.4 \pm 2.1 \mathrm{a}$ & $90.2 \pm 4.7 \mathrm{a}$ \\
DQ-HX & $3.7 \pm 0.2 \mathrm{c}$ & $65.1 \pm 2.4 \mathrm{ab}$ & $55.3 \pm 2.1 \mathrm{a}$ & $3.2 \pm 0.8 \mathrm{~b}$ & $3.7 \pm 1.6 \mathrm{ab}$ & $61.0 \pm 1.4 \mathrm{ab}$ & $90.6 \pm 3.5 \mathrm{a}$ \\
DQ-SCCO2 & $3.4 \pm 0.1 \mathrm{~b}$ & $65.9 \pm 2.6 \mathrm{~b}$ & $56.2 \pm 2.3 \mathrm{a}$ & $1.1 \pm 1.1 \mathrm{a}$ & $4.1 \pm 0.9 \mathrm{~b}$ & $62.2 \pm 1.5 \mathrm{~b}$ & $90.4 \pm 3.7 \mathrm{a}$ \\
\hline
\end{tabular}

FSG: Free sugar glucose; RAG: rapidly available glucose; RDS: rapidly digestible starch, SDS: slowly digestible starch, RS: resistant starch; TS: total starch, and SDRI: starch digestion rate index.

Data are the mean \pm standard deviation $(n=6)$. Values with a letter in common in the same column are not significantly different $(\mathrm{p}<0.05)$.

\section{Conclusions}

The results of this study revealed that the defatted-quinoa obtained as a coproduct of quinoa oil extraction by $\mathrm{SCCO}_{2}$ can be considered a promising source for sustainable food production. Other components beyond lipids such as starch, fiber and protein contribute in a greater extent to physicochemical properties of whole grain quinoa. Quinoa defatted with $\mathrm{SCCO}_{2}$ showed a disrupted and microporous structure as a result of having been subjected to pressure. However, only slight changes with respect to native quinoa, such as lower pasting and gelatinization 
temperatures and slightly higher gelatinization and retrogradation enthalpies, were observed. The viscometric profile of $\mathrm{DQ}-\mathrm{SCCO}_{2}$ was similar to that of native quinoa, NDQ, and significantly higher than that of DQ-HX. The work confirms that defatted quinoa flour obtained as coproduct by supercritical $\mathrm{CO}_{2}$ extraction of quinoa oil could be used directly in the food industry as a valuable material without solvent residues maintaining a technological quality superior to that obtained for quinoa defatted by extraction with organic solvents.

\section{Acknowledgement}

The authors thank the financial support of the Ministerio de Economía y Competitividad and the European Regional Development Fund (FEDER) (AGL2015-63849-C2-2-R) and the Junta de Castilla y León/FEDER VA072P17. We also thank Joanna Harasym for her technical comments and support during the development of the work and IESMAT (Madrid, España) for the determination of the particle size distribution of quinoa samples with Mastersizer 3000.

\section{References}

AACC. (1999). AACC International Methods, 44-19.01. Moisture-Air-Oven Method. AACC International Approved Methods. https://doi.org/10.1016/j.beem.2005.04.006

AACC. (2014). AACC International Method, 76-31.01. Determination of Damaged StarchSpectrophotometric Method. AACC International Approved Methods. https://doi.org/10.1094/AACCIntMethod-76-33.01

Abebe, W., Collar, C., \& Ronda, F. (2015). Impact of variety type and particle size distribution on starch enzymatic hydrolysis and functional properties of tef flours. Carbohydrate Polymers, 115, 260-268. https://doi.org/10.1016/j.carbpol.2014.08.080

Abugoch James, L. E. (2009). Quinoa (Chenopodium quinoa Willd.): Composition, chemistry, nutritional, and functional properties. In Advances in Food and Nutrition Research (Vol. 58, pp. 1-31). https://doi.org/10.1016/S1043-4526(09)58001-1

Annor, G. A., Marcone, M., Bertoft, E., \& Seetharaman, K. (2013). In vitro starch digestibility and expected glycemic index of kodo millet (Paspalum scrobiculatum) as affected by starchprotein-lipid interactions. Cereal Chemistry, 90(3), 211-217. https://doi.org/10.1094/CCHEM-06-12-0074-R

Avila Ruiz, G., Arts, A., Minor, M., \& Schutyser, M. (2016). A Hybrid Dry and Aqueous Fractionation Method to Obtain Protein-Rich Fractions from Quinoa (Chenopodium quinoa Willd). Food and Bioprocess Technology, 9(9), 1502-1510. https://doi.org/10.1007/s11947-016-1731-0

Benito-Román, O., Rodríguez-Perrino, M., Sanz, M. T., Melgosa, R., \& Beltrán, S. (2018). Supercritical carbon dioxide extraction of quinoa oil: Study of the influence of process parameters on the extraction yield and oil quality. Journal of Supercritical Fluids, 139(May), 62-71. https://doi.org/10.1016/j.supflu.2018.05.009

Brinegar, C., \& Goundan, S. (1993). Isolation and Characterization of Chenopodin, the 11S Seed Storage Protein of Quinoa (Chenopodium quinoa). Journal of Agricultural and Food Chemistry, 4l(2), 182-185. https://doi.org/10.1021/jf00026a006

Brito, I. L., de Souza, E. L., Felex, S. S. S., Madruga, M. S., Yamashita, F., \& Magnani, M. (2015). Nutritional and sensory characteristics of gluten-free quinoa (Chenopodium quinoa Willd)-based cookies development using an experimental mixture design. Journal of Food Science and Technology, 52(9), 5866-5873. https://doi.org/10.1007/s13197-014-1659-1 
Brown, K., \& Submitted, T. (2000). The Drying of Foods Using Supercritical Carbon Dioxide. https://doi.org/10.1007/s10661-007-9794-z

Cappa, C., Lucisano, M., Barbosa-Cánovas, G. V., \& Mariotti, M. (2016). Physical and structural changes induced by high pressure on corn starch, rice flour and waxy rice flour. Food Research International, 85, 95-103. https://doi.org/10.1016/j.foodres.2016.04.018

Cocozza, C., Pulvento, C., Lavini, A., Riccardi, M., d'Andria, R., \& Tognetti, R. (2013). Effects of increasing salinity stress and decreasing water availability on ecophysiological traits of quinoa (Chenopodium quinoa Willd.) grown in a mediterranean-type agroecosystem. Journal of Agronomy and Crop Science, 199(4), 229-240. https://doi.org/10.1111/jac.12012

Eliasson, A. -C, \& Ljunger, G. (1988). Interactions between amylopectin and lipid additives during retrogradation in a model system. Journal of the Science of Food and Agriculture, 44(4), 353-361. https://doi.org/10.1002/jsfa.2740440408

Englyst, K. N., Englyst, H. N., Hudson, G. J., Cole, T. J., \& Cummings, J. H. (1999). Rapidly available glucose in foods: An in vitro measurement that reflects the glycemic response. American Journal of Clinical Nutrition, 69(3), 448-454. https://doi.org/10.1002/15213803(20020701)46:4<240::AID-FOOD240>3.0.CO;2-1

Englyst, K. N., Hudson, G. J., \& Englyst, H. N. (2006). Starch Analysis in Food. Encyclopedia of Analytical Chemistry, 1-17. https://doi.org/10.1002/9780470027318.a1029

Filho, A. M. M., Pirozi, M. R., Borges, J. T. D. S., Pinheiro Sant'Ana, H. M., Chaves, J. B. P., \& Coimbra, J. S. D. R. (2017). Quinoa: Nutritional, functional, and antinutritional aspects. Critical Reviews in Food Science and Nutrition, 57(8), 1618-1630. https://doi.org/10.1080/10408398.2014.1001811

Föste, M., Nordlohne, S. D., Elgeti, D., Linden, M. H., Heinz, V., Jekle, M., \& Becker, T. (2014). Impact of quinoa bran on gluten-free dough and bread characteristics. European Food Research and Technology, 239(5), 767-775. https://doi.org/10.1007/s00217-014-2269-x

Gibson, T. S., Solah, V. A., \& McCleary, B. V. (1997). A procedure to measure amylose in cereal starches and flours with concanavalin A. Journal of Cereal Science, 25(2), 111-119. https://doi.org/10.1006/jcrs.1996.0086

Joshi, A. U., Liu, C., \& Sathe, S. K. (2015). Functional properties of select seed flours. LWT Food Science and Technology, 60(1), 325-331. https://doi.org/10.1016/j.lwt.2014.08.038

Kang, S. W., Rahman, M. S., Kim, A. N., Lee, K. Y., Park, C. Y., Kerr, W. L., \& Choi, S. G. (2017). Comparative study of the quality characteristics of defatted soy flour treated by supercritical carbon dioxide and organic solvent. Journal of Food Science and Technology, 54(8), 2485-2493. https://doi.org/10.1007/s13197-017-2691-8

Kaushal, P., Kumar, V., \& Sharma, H. K. (2012). Comparative study of physicochemical, functional, antinutritional and pasting properties of taro (Colocasia esculenta), rice (Oryza sativa) flour, pigeonpea (Cajanus cajan) flour and their blends. LWT - Food Science and Technology, 48(1), 59-68. https://doi.org/10.1016/j.lwt.2012.02.028

Koziol, M. J. (1992). Chemical Composition and Nutritional Evaluation of Quinoa (Chenopodium quinoa Willd.). JOURNAL OF FOOD COMPOSITION AND ANALYSIS, 5, 35-68.

Koziol, M. J. (1993). Quinoa: A potencial new oil crop. In J. Janick and J.E. Simon (Ed.), New crops (pp. 328-336). Wiley, New York.

Li, G., Wang, S., \& Zhu, F. (2016). Physicochemical properties of quinoa starch. Carbohydrate Polymers, 137, 328-338. https://doi.org/10.1016/j.carbpol.2015.10.064

Li, G., \& Zhu, F. (2017a). Amylopectin molecular structure in relation to physicochemical 
properties of quinoa starch. Carbohydrate Polymers, 164, 396-402. https://doi.org/http://dx.doi.org/10.1016/j.carbpol.2017.02.014

Li, G., \& Zhu, F. (2017b). Molecular structure of quinoa starch. Carbohydrate Polymers, 158, 124-132. https://doi.org/10.1016/j.carbpol.2016.12.001

Li, G., \& Zhu, F. (2017c). Physicochemical properties of quinoa flour as affected by starch interactions. Food Chemistry, 221, 1560-1568. https://doi.org/10.1016/j.foodchem.2016.10.137

Li, G., \& Zhu, F. (2018). Quinoa starch: Structure, properties, and applications. Carbohydrate Polymers, 181(September 2017), 851-861. https://doi.org/10.1016/j.carbpol.2017.11.067

Lijuan, S., Guiying, Z., Guoan, Z., \& Zaigui, L. (2007). Effects of different milling methods on flour quality and performance in steamed breadmaking. Journal of Cereal Science, 45(1), 18-23. https://doi.org/10.1016/j.jcs.2006.02.004

Mufari, J. R., Miranda-Villa, P. P., \& Calandri, E. L. (2018). Quinoa germ and starch separation by wet milling, performance and characterization of the fractions. Lwt, 96(June), 527-534. https://doi.org/10.1016/j.lwt.2018.06.010

Mukhopadhyay, M. (2000). Natural Extracts Using Supercritical Carbon Dioxide. CRC Press.

Ng, S. C., Anderson, A., Coker, J., \& Ondrus, M. (2006). Characterization of lipid oxidation products in quinoa (Chenopodium quinoa). Food Chemistry, 101(1), 185-192. https://doi.org/10.1016/j.foodchem.2006.01.016

Peterson, S. C., Eller, F. J., Fanta, G. F., Felker, F. C., \& Shogren, R. L. (2008). Comparison of the effects of critical fluid and reflux-extracted techniques on cornstarch pasting properties. Carbohydrate Polymers, 71(1), 74-79. https://doi.org/10.1016/j.carbpol.2007.05.019

Repo-Carrasco, R., Espinoza, C., \& Jacobsen, S. E. (2003). Nutritional value and use of the andean crops quinoa (Chenopodium quinoa) and kañiwa (Chenopodium pallidicaule). Food Reviews International, 19(1-2), 179-189. https://doi.org/10.1081/FRI-120018884

Ronda, F., \& Roos, Y. H. (2008). Gelatinization and freeze-concentration effects on recrystallization in corn and potato starch gels. Carbohydrate Research, 343(5), 903-911. https://doi.org/10.1016/j.carres.2008.01.026

Russin, T. A., Boye, J. I., Arcand, Y., \& Rajamohamed, S. H. (2011). Alternative Techniques for Defatting Soy: A Practical Review. Food and Bioprocess Technology, 4(2), 200-223. https://doi.org/10.1007/s11947-010-0367-8

Schoenlechner, R., Drausinger, J., Ottenschlaeger, V., Jurackova, K., \& Berghofer, E. (2010). Functional Properties of Gluten-Free Pasta Produced from Amaranth, Quinoa and Buckwheat. Plant Foods for Human Nutrition, 65(4), 339-349. https://doi.org/10.1007/s11130-010-0194-0

Sibakov, J. K., Kirjoranta, S. J., Alam, S. A., Kokkonen, H., Jurvelin, J. S., Jouppila, K., ... Sozer, N. (2015). Effect of Oat Bran Fractions on Extrudates Made of Defatted Oats. Food and Bioprocess Technology, 8(2), 445-458. https://doi.org/10.1007/s11947-014-1425-4

Srichuwong, S., Curti, D., Austin, S., King, R., Lamothe, L., \& Gloria-Hernandez, H. (2017). Physicochemical properties and starch digestibility of whole grain sorghums, millet, quinoa and amaranth flours, as affected by starch and non-starch constituents. Food Chemistry, 233, 1-10. https://doi.org/10.1016/j.foodchem.2017.04.019

Tang, H., Watanabe, K., \& Mitsunaga, T. (2002). Characterization of storage starches from quinoa, barley and adzuki seeds. Carbohydrate Polymers, 49(1), 13-22. https://doi.org/10.1016/S0144-8617(01)00292-2

Temelli, F., Stobbe, K., Rezaei, K., \& Vasanthan, T. (2013). Tocol composition and supercritical 
carbon dioxide extraction of lipids from barley pearling flour. Journal of Food Science, 78(11). https://doi.org/10.1111/1750-3841.12271

Turkut, G. M., Cakmak, H., Kumcuoglu, S., \& Tavman, S. (2016). Effect of quinoa flour on gluten-free bread batter rheology and bread quality. Journal of Cereal Science, 69, 174-181. https://doi.org/10.1016/j.jcs.2016.03.005

Vasanthan, T., \& Hoover, R. (1992). Effect of physical modification on starch structure and physicochemical properties. Food Chemistry, 45, 337-347. Retrieved from http://ebooks.cambridge.org/ref/id/CBO9781107415324A009

Vega-Gálvez, A., Miranda, M., Vergara, J., Uribe, E., Puente, L., \& Martínez, E. A. (2010). Nutrition facts and functional potential of quinoa (Chenopodium quinoa willd.), an ancient Andean grain: A review. Journal of the Science of Food and Agriculture, 90(15), 25412547. https://doi.org/10.1002/jsfa.4158

Walters, M., Lima Ribeiro, A. P., Hosseinian, F., \& Tsopmo, A. (2018). Phenolic acids, avenanthramides, and antioxidant activity of oats defatted with hexane or supercritical fluid. Journal of Cereal Science, 79, 21-26. https://doi.org/10.1016/j.jcs.2017.09.010

Wang, S., \& Zhu, F. (2016). Formulation and Quality Attributes of Quinoa Food Products. Food and Bioprocess Technology, 9(1), 49-68. https://doi.org/10.1007/s11947-015-1584-y

Wejnerowska, G., \& Ciaciuch, A. (2018). Optimisation of Oil Extraction from Quinoa Seeds with Supercritical Carbon Dioxide with Co-solvents, 2018(1), 81-87. https://doi.org/10.1074/jbc.M705669200

Ye, J., Hu, X., Luo, S., McClements, D. J., Liang, L., \& Liu, C. (2018). Effect of endogenous proteins and lipids on starch digestibility in rice flour. Food Research International, 106(January), 404-409. https://doi.org/10.1016/j.foodres.2018.01.008 